\title{
Virological outcome among HIV-1 infected patients on first-line antiretroviral treatment in semi-rural HIV clinics in Togo
}

\author{
Abla A. Konou ${ }^{1}$, Mounerou Salou $^{1,2}$, Nicole Vidal ${ }^{3}$, Pascal Kodah ${ }^{4}$, Damobé Kombate ${ }^{5}$, Pyabalo Kpanla ${ }^{6}$, \\ Tchabia Nabroulaba ${ }^{7}$, Djifa Nyametso ${ }^{8}$, Assétina Singo-Tokofaï ${ }^{9}$, Palokinam Pitche ${ }^{10}$, Eric Delaporte ${ }^{3}$, \\ Mireille Prince-David ${ }^{1,2}$, Martine Peeters ${ }^{3}$ and Anoumou Y. Dagnra ${ }^{1,2,11^{*}}$
}

\begin{abstract}
Background: Access to antiretroviral treatment (ART) in resource-limited countries has increased significantly but scaling-up ART into semi-rural and rural areas is more recent. Information on treatment outcome in such areas is still very limited notably due to additional difficulties to manage ART in these areas.

Results: $387 \mathrm{HIV}-1$ infected adults ( $\geq 18$ years) were consecutively enrolled when attending healthcare services for their routine medical visit at 12 or 24 months on first-line ART in five HIV care centers (four semi-rural and one rural). Among them, 102 patients were on first-line ART for $12 \pm 2$ months (M12) and 285 for $24 \pm 2$ months (M24). Virological failure was observed in 70 (18.1\%) patients ranging from 13.9 to $31.6 \%$ at M12 and from 8.1 to $22.4 \%$ at M24 across the different sites. For $67 / 70$ patients, sequencing was successful and drug resistance mutations were observed in $65(97 \%)$. The global prevalence of drug resistance in the study population was thus at least $16.8 \%$ (65/387). Moreover, 32 (8.3\%) and 27 (6.9\%) patients were either on a completely ineffective ART regime or with only a single drug active. Several patients accumulated high numbers of mutations and developed also cross-resistance to abacavir, didanosine or the new NNRTI drugs like etravirine and rilpivirine.
\end{abstract}

Conclusion: The observations on ART treatment outcome from ART clinics in semi-rural areas are close to previous observations in Lomé, the capital city suggesting that national ART-programme management plays a role in treatment outcome.

Keywords: HIV, Antiretroviral treatment, Drug resistance, Semi-rural, Public health, Togo, Africa

\section{Findings \\ Background}

Scale-up of antiretroviral treatment (ART) programs in resource-limited countries was possible because standardized first and second line antiretroviral (ARV) combinations and clinical and/or immunological criteria to start and monitor ART were used as recommended by WHO [1]. However, heterogeneous treatment outcomes have been observed in the national ART programs from

\footnotetext{
*Correspondence: a.dagnra@yahoo.fr

${ }^{11} 08$ B.P. 8742, Lomé 08, Togo

Full list of author information is available at the end of the article
}

different countries, most likely related to ART-programme management [2]. As such, virological failure can range from less than $3 \%$ to more than $20 \%$ in patients on ART for 12 or 24 months [2-4].

In Togo, a country of six million inhabitants in West Africa, scaling-up of ART started in 2007 in Lomé, the capital city, and has expanded to semi-rural areas in 2008. In 2013, almost $50 \%$ of patients who were in need for ART according to WHO guidelines from 2010 (CD4 count <350) were receiving ART [5]. Previous studies in ART clinics in Lomé showed high virological failure related to ARV drug resistance, i.e. in 13 to $25 \%$ of the patients receiving ART for 12 or 24 months [2, 6]. Given the additional difficulties to manage ART in these areas 
(distances to clinics, scarce human resources, drug stockouts, etc.) together with high rates of ARV drug resistance in the capital city, it was important to evaluate also virological outcome and emergence of drug resistance in ART clinics located in semi-urban and rural areas in Togo.

\section{Methods Study sites and population}

A cross-sectional study was conducted in 2012 between January and July in five HIV care centers that administer ARV drugs and monitor treatment. They were located in four semi-rural cities: Aného (AN), Kpalimé (KP), Atakpamé (AT) and Kara (KA) at respectively 60, 120, 160 and $410 \mathrm{~km}$ from Lomé, the capital city, and in one rural city, Kouvé (KO) at $70 \mathrm{~km}$ distance from Lomé (Fig. 1). HIV-1 infected adults ( $\geq 18$ years) were consecutively enrolled when attending clinics for their routine medical visit at $12 \pm 2$ months or $24 \pm 2$ months on first-line ART. This study was approved by the National Ethics Committee ( ${ }^{\circ} 751 / 2014 / M S / C A B /$ DGS/DPLET/CBRS). Informed consent was obtained for each participating patient. Questionnaires were used to collect epidemiological and demographic information and ART history was obtained from on-site medical records. Whole blood was drawn and plasma was separated by centrifugation. Plasma aliquots were stored at $-20{ }^{\circ} \mathrm{C}$ for maximum 1 week on site and were subsequently transported by road in a cool box to the Laboratoire de Biologie Moléculaire et d'Immunologie (BIOLIM/FSS-UL) where they were stored at $-80{ }^{\circ} \mathrm{C}$ until use.

\section{Virological analyses}

HIV-1 viral load (VL) was determined with EasyQ HIV assay (Biomerieux, Capronne, France) or RealTime m2000rt (Abbott Pack, IL, USA) in Lomé (BIOLIM/FSS$\mathrm{UL})$. According to WHO recommendations, genotypic drug resistance testing was done in a WHO accredited laboratory (IRD, Montpellier, France) on patients with $\mathrm{VL} \geq 1000$ copies/ml. Protease and partial Reverse Transcriptase (RT) were amplified with the in-house protocol from the Agence Nationale de Recherche sur le Sida et les Hépatites en France (ANRS) [2, 7]. Drug resistance mutations (DRM) were identified using the ANRS interpretation algorithm, version 24 [7]. The newly reported sequences are available in GenBank under the following accession numbers: KR047793-KR047859.

\section{Results}

A total of 387 patients were consecutively enrolled during their follow-up visit at $12 \pm 2(\mathrm{M} 12, \mathrm{n}=102)$ or
$24 \pm 2(\mathrm{M} 24, \mathrm{n}=285)$ months on ART. Table 1 shows patients characteristics at each site. Overall, more women were enrolled than men: 84/102 (82.4\%) at M12 and 205/285 (71.9\%) at M24. The median age of patients was 36 (IQR 31-42) and 39 years (IQR 33-45) at M12 and M24, respectively. More than $97 \%$ (277/285) of patients have been exposed to the following drugs in their first line regimen: stavudine $(\mathrm{d} 4 \mathrm{~T})$ and/or zidovudine (AZT) plus lamivudine (3TC) plus nevirapine (NVP) and/or efavirenz (EFV). For 302 (78 \%) patients, $\mathrm{d} 4 \mathrm{~T}$ was replaced by AZT because national guidelines were changed. Only eight $(2.8 \%)$ patients switched to tenofovir (TDF) instead of AZT or d4T. At ART initiation the overall median CD4 count $/ \mathrm{mm}^{3}$ was 176 (IQR 86-261) and 152 (IQR 88-219) for the patients who were on ART for $12 \pm 2$ and $24 \pm 2$ months, respectively. Overall, 153/373 (41.1 \%) and 220/373 (58.9\%) of the patients were in WHO stages 1 or 2 and WHO stages 3 or 4, respectively at ART start. However, CD4 counts and WHO stages at ART initiation could vary across the different sites (Table 1).

Seventy patients (18.1 \%; CI95 14.5-22.2 \%) had VL >1000 copies/ml; 20/102 (19.6 \%; CI95 13.4-29.2\%) at M12 and 50/285 (17.5\%; CI95 13.5-22.4\%) at M24. Virological failure ranged from 13.9 to $31.6 \%$ at M12 and from 8.1 to $22.4 \%$ at M24. For 67 (95.7 \%) patients, sequencing was successful and DRM were observed in 65 (97\%) of them; i.e. 20/20 at M12 and 45/47 at M24. Among the 65 drug resistant HIV strains, 59 were resistant to NRTIs and NNRTIs, two to NRTIs only and four to NNRTIs only. The global prevalence of drug resistance in the study population was thus at least $16.8 \%(13.4-20.9 \%, 95 \%$ CI) $(65 / 387)$, but 27 patients (6.9\%; 4.8-9.9\%, $95 \% \mathrm{CI})$ were infected with HIV strains resistant to two of the three first-line ARVs and $32(8.3 \% ; 5.9-11.4 \%, 95 \% \mathrm{CI})$ to all three first line ARVs.

As expected, the observed DRM were associated with the drugs used in first-line regimens (Table 2). M184 V selected by $3 \mathrm{TC}$ was the most frequent NRTI mutation, 56/65 (86.2 \%). Frequently observed TAMs included M41L, D67 N/D, K70R, K219E/Q and T215Y/F. The K65R mutation was seen in two patients. One-third of the patients had at least 3 or more NRTI mutations and several patients were already predicted to be resistant to $\mathrm{ABC}(\mathrm{n}=12)$, DDI $(\mathrm{n}=2)$ or tenofovir (TDF) $(\mathrm{n}=3)$. Among NNRTI mutations, Y181C/Y and K103N were most frequently observed and 15 (23.1\%) patients accumulated at least three NNRTI mutations, with $14(21.5 \%)$ and $44(67.7 \%)$ that were predicted to be resistant to second line NNRTIs ETV and RPV, respectively. 


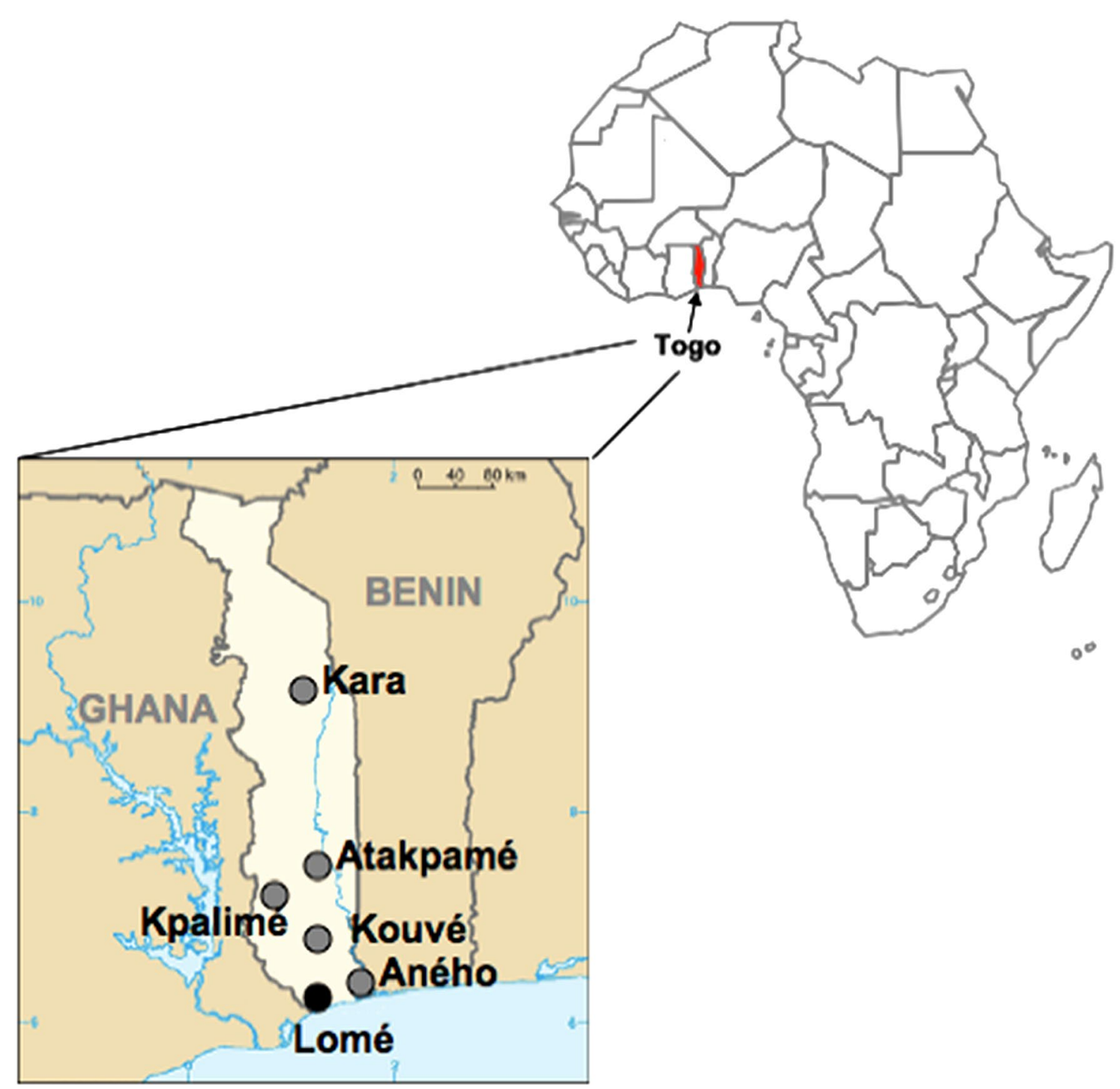

Fig. 1 Togo map indicating locations of the healthcare centers where patients were enrolled. The sites where samples were collected for this study are indicated with grey full circles, and the name of the corresponding city at the right. Lomé, the capital city, is indicated with a black full circle

\section{Discussion}

Overall, we showed that $18 \%$ of patients on ART for 12 or 24 months in semi-rural and rural ART clinics were on virological failure and almost all of them (97\%) were infected with drug resistant HIV-1 strains. These observations are high and close to what has been noticed in previous studies from Lomé, the capital city; for example in a survey conducted about 1 year earlier in 2010/2011 using the same cross-sectional approach, $19 \%(124 / 642)$ of patients for 12 or 24 months on ART were infected with HIV drug resistant strains [2]. Our study confirms thus a high ART failure in Togo in general and which is higher than observed in other countries, when comparing with studies that used a similar approach [2]. Scaleup of ART started in 2007 in the capital city and was expanded to semi-rural areas in 2008. Between 2006 and 2012, the number of patients on ART increased from 6700 to 31,500 but tools to monitor patients did not follow this scale-up and training of medical personnel was insufficient to allow early detection of side_effects of certain ARVs, evaluate adherence or recognize rapidely decline of clinical status. In addition, the national 


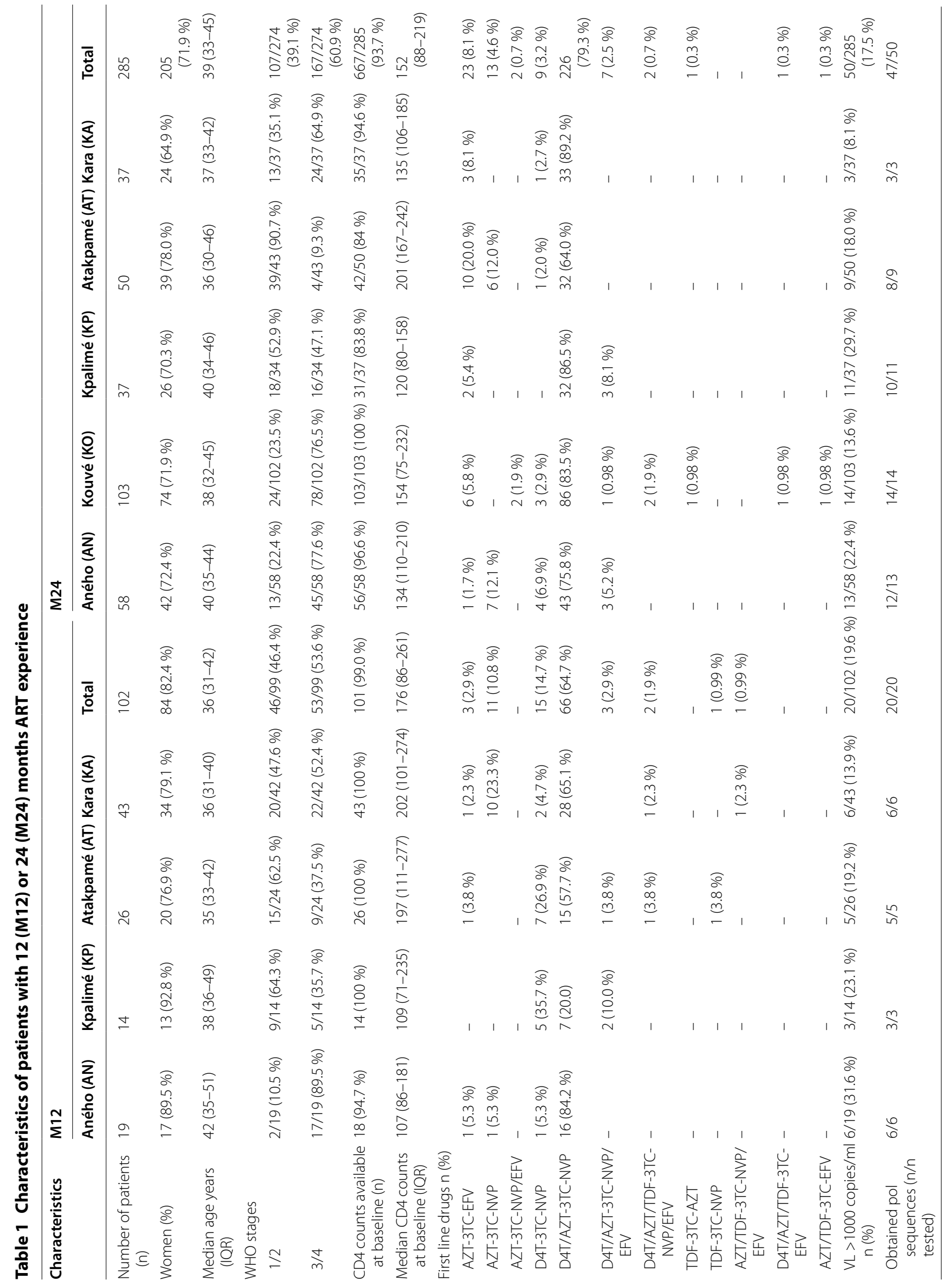




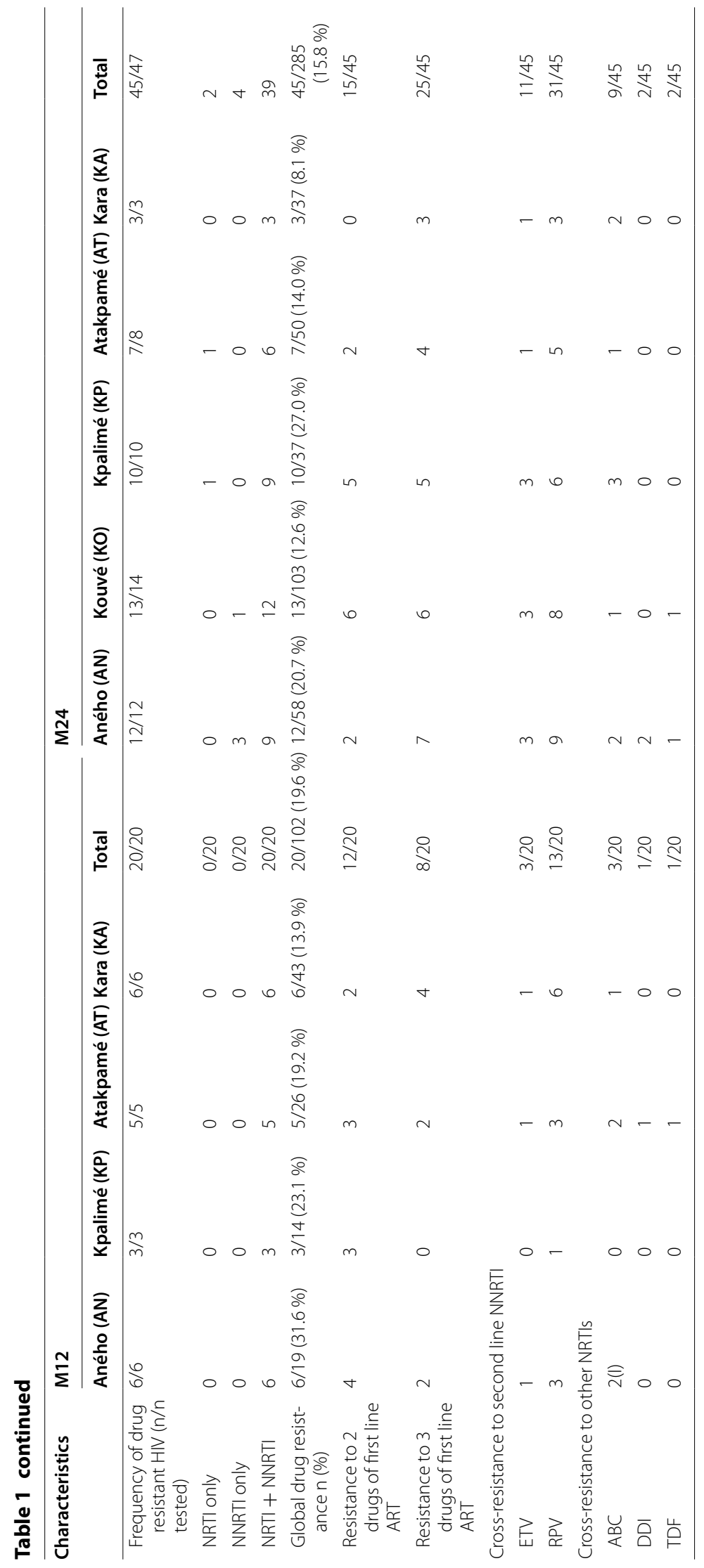


Table 2 Drug resistance mutations to the first line antiretroviral drugs after 12 and 24 months on ART

\begin{tabular}{|c|c|c|c|c|c|}
\hline Patient code & Months on ART & NNRTI mutations & NRTI mutations & Subtype/CRF & Accession \\
\hline AN021 & 12 & Y181V & M41LM, M184V, T215F & A3 & KR047796 \\
\hline AN026 & 12 & A98S, Y181C, G190A & M41L, A62V, M184V, K219N & CRF02_AG & KR047798 \\
\hline AN052 & 12 & K103KN & M184V & CRF06_cpx & KR047805 \\
\hline AN058 & 12 & V106A & A62AV, M184V & CRF02_AG & KR047807 \\
\hline AN059 & 12 & $\mathrm{~K} 103 \mathrm{~N}$ & M41L, M184V, T215Y & CRF02_AG & KR047808 \\
\hline AN074 & 12 & K101E, G190A & M184V & CRF06_cpx & KR047810 \\
\hline AT407 & 12 & K101E, G190A & M41L, D67N, K70R, V75IM, T215F, K219Q & URF & KR047840 \\
\hline AT411 & 12 & Y181C, G190A & M184V & URF & KR047841 \\
\hline AT423 & 12 & $\mathrm{~K} 103 \mathrm{~N}$ & M184V & CRF06_cpx & KR047843 \\
\hline AT426 & 12 & V901, K101EQ, Y181C, G190S & K65R & CRF02_AG & KR047844 \\
\hline AT477 & 12 & $\mathrm{~K} 103 \mathrm{~N}$ & M184I & G & KR047850 \\
\hline KA305 & 12 & Y181C & M41L, M184V & CRF06_cpx & KR047851 \\
\hline KA308 & 12 & $\mathrm{~K} 103 \mathrm{~N}, \mathrm{Y} 181 \mathrm{C}, \mathrm{H} 221 \mathrm{Y}$ & M184V, T215Y & CRF06_cpx & KR047852 \\
\hline KA348 & 12 & Y181C & M184V & CRF06_cpx & KR047855 \\
\hline KA350 & 12 & K101E, G190A & M41L, M184V & URF & KR047856 \\
\hline KA378 & 12 & Y181C & M41L, M184V, L210W, T215Y & URF & KR047858 \\
\hline KA379 & 12 & K103N, Y181C & M184I & CRF02_AG & KR047859 \\
\hline KP206 & 12 & A98S, K103N, P225H & M184V & C & KR047826 \\
\hline KP218 & 12 & K101EK, G190A & M184V & CRF06_cpx & KR047829 \\
\hline KP280 & 12 & $\mathrm{~K} 103 \mathrm{~N}$ & M184V & CRF02_AG & KR047837 \\
\hline AN008 & 24 & V179I, Y181CY, G190AG & - & URF & KR047793 \\
\hline AN012 & 24 & K103N & - & CRF02_AG & KR047794 \\
\hline AN019 & 24 & Y181C, H221Y & M41L, V75I, M184V, T215F & CRF02_AG & KR047795 \\
\hline AN022 & 24 & Y181C & M184V & URF & KR047797 \\
\hline AN028 & 24 & A98S, Y181C & D67N, K70R, T215F, K219E & CRF02_AG & KR047799 \\
\hline AN032 & 24 & Y181CY, G190AG, H221HY & - & URF & KR047800 \\
\hline AN041 & 24 & K103N, Y181C & A62V, K65R, K70T, V75I, F116Y, Q151M, M184V & CRF02_AG & KR047801 \\
\hline AN043 & 24 & K101E, Y181C, G190A & M184V, T215F & CRF02_AG & KR047802 \\
\hline AN048 & 24 & Y181C & D67N, K70R, T215F, K219E & CRF02_AG & KR047803 \\
\hline AN049 & 24 & K103N & M184V & CRF06_cpx & KR047804 \\
\hline AN054 & 24 & K103N & M41L, E44D, L74I, M184V, L210W, T215Y & CRF02_AG & KR047806 \\
\hline AN068 & 24 & Y181C, H221Y & M41LM, M184V, T215Y & CRF02_AG & KR047809 \\
\hline AT400 & 24 & Y181C & K70KR, M184V & CRF02_AG & KR047838 \\
\hline AT403 & 24 & - & M184V & $\mathrm{A} 3$ & KR047839 \\
\hline AT420 & 24 & K103N & M184V & CRF02_AG & KR047842 \\
\hline AT435 & 24 & Y181C, H221Y & M41LM, D67DN, K70KR, T215Y, K219EK & CRF02_AG & KR047845 \\
\hline AT442 & 24 & Y181C & M184V,T215FIST & CRF02_AG & KR047846 \\
\hline AT452 & 24 & Y181C & M41L, M184V, T215Y & CRF02_AG & KR047847 \\
\hline AT456 & 24 & K101E, G190A & M184V, T215F & CRF02_AG & KR047848 \\
\hline AT463 & 24 & - & - & CRF02_AG & KR047849 \\
\hline KA319 & 24 & A98S, K103N, Y181C & D67N, K70R, M184V, T215F, K219Q & URF & KR047853 \\
\hline KA344 & 24 & K101E, G190A & M41L, D67DN, K70KR, M184V, T215Y & G & KR047854 \\
\hline KA366 & 24 & K101E, Y181C, G190A & M41L, M184V, L210W, T215Y & URF & KR047857 \\
\hline KO100 & 24 & Y181C & M41L, M184V,T215F & CRF06_cpx & KR047811 \\
\hline $\mathrm{KO} 112$ & 24 & K103N, P225H & K70DEKN, M184V & CRF02_AG & KR047812 \\
\hline KO116 & 24 & K103N & M184V & URF & KR047813 \\
\hline KO122 & 24 & Y181C, H221Y & M41L, D67N, K70R, M184V, T215Y & G & KR047814 \\
\hline KO130 & 24 & K103N, E138 K & M184V,T215F & CRF02_AG & KR047815 \\
\hline KO137 & 24 & V179I, G190A, M230L & M184V, T215Y & $\mathrm{A} 3$ & KR047816 \\
\hline
\end{tabular}


Table 2 continued

\begin{tabular}{|c|c|c|c|c|c|}
\hline Patient code & Months on ART & NNRTI mutations & NRTI mutations & Subtype/CRF & Accession \\
\hline KO148 & 24 & K103N & M184V & CRF02_AG & KR047817 \\
\hline KO150 & 24 & $\mathrm{~K} 103 \mathrm{~N}, \mathrm{Y} 181 \mathrm{C}$ & M184V & CRF02_AG & KR047818 \\
\hline KO158 & 24 & A98AG, K101E, Y181C & D67N, K70R, M184V, T215F, K219E & URF & KR047819 \\
\hline KO193 & 24 & K103N & M184V & CRF02_AG & KR047820 \\
\hline K0195 & 24 & Y181CY & - & CRF02_AG & KR047821 \\
\hline K0197 & 24 & V90I, V179I, G190A & M184V & A3 & KR047822 \\
\hline KO200 & 24 & E138EG & - & URF & KR047823 \\
\hline $\mathrm{KO} 203$ & 24 & Y181C, H221Y & M184V, T215Y, & CRF06_cpx & KR047824 \\
\hline KP202 & 24 & Y181C, H221Y & M184V, T215Y & CRFO2_AG & KR047825 \\
\hline KP210 & 24 & G190S & M184V & CRFO2_AG & KR047827 \\
\hline KP213 & 24 & K103N & M184V, T215ST & CRFO2_AG & KR047828 \\
\hline KP221 & 24 & A98AS, K103N, E138Q, & M41L, V75I, M184 V, T215F & URF & KR047830 \\
\hline KP223 & 24 & K103N, Y181C,H221Y & M41L, D67N, K70R, V75I, M184V, T215F, K219E, & CRF02_AG & KR047831 \\
\hline KP234 & 24 & K103N & M41L, M184V & CRF06_cpx & KR047832 \\
\hline KP235 & 24 & V90IV, A98AG, E138Q, V179T & M184V & CRF02_AG & KR047833 \\
\hline KP241 & 24 & Y181V, H221Y & M41L, M184V, L210W, T215F & CRFO2_AG & KR047834 \\
\hline KP243 & 24 & K101E, G190A & M41L, D67N, M184V, L210W, T215Y & URF & KR047835 \\
\hline KP253 & 24 & K103N & M184V & CRFO2_AG & KR047836 \\
\hline
\end{tabular}

program encountered problems with stock management resulting in ARV drug substitution with the same molecules, administered separately as individual pills instead as a fixed dosed combination, or even interruption of the treatment. It is known that non-adherence and treatment interruption may favor emergence of drug resistance.

Today, only very few studies reported observations on ART outcome from semi-rural or rural areas in resource limited settings, especially from Africa $[2,8,9]$. In Cameroon, $10 \%$ of patients were infected with drug resistant HIV strains after a median of 12 months on ART in rural district hospitals at 50 to $150 \mathrm{~km}$ distance from Yaoundé, the capital city [10], which is close to rates observed in Yaoundé [2]. However, in a rural health center in Kolofata, at the extreme north of Cameroon at $1200 \mathrm{~km}$ from the capital city and with difficult connections, almost $30 \%$ of patients on ART (median of 24 months) were resistant to ARV drugs [11]. Another report showed equal proportions of drug resistance in urban and rural areas, between 9.2 to $15.9 \%$ after a median of 36 months on ART in Senegal, Mali and Guinea [12]. In rural and semi-rural settings in Gabon, $21 \%$ of patients were resistant after a median of 33 months on ART [13]. In a rural clinic in Tanzania, rates of drug resistance were low and ranged from 4 to $8 \%$ of patients after 1 or 2 years on ART, respectively [14]. Although, it is important to note that comparing results among the different studies mentioned above has to be taken with caution, because study design can differ as well as viral load capacities and techniques to identify virological failure.
Overall it seems that treatment outcome varies among countries, but within countries treatment outcome in semi-rural settings seem to be similar to those in urban settings except in extreme conditions. These observations are in line with the fact that national ART-programme management plays a role in treatment outcome in resource-limited countries [2]. It is important to note that we provided only information on the proportion of drug resistance in HIV infected patients who are still on ART and have no information on follow-up or mortality rates. Prospective studies where loss of follow-up are considered as treatment failures, would probable yield higher virological failure rates. Previous studies showed a higher mortality rate and loss of follow up in rural areas during the first 3 years [15].

Like in other reports on treatment outcome, several patients in our survey accumulated high numbers of mutations and developed also cross-resistance to potential second and/or third line drugs [16-18]. In addition these multi-drug resistant strains can also be transmitted and have a negative impact on future efficiency of first line regimens.

\section{Conclusions}

The observations on ART treatment outcome in semirural areas show high failure rate but are close to those in Lomé, the capital city. Lowering the rates of drug resistance represents a challenge for the country. The first goals will be to identify factors associated with drug resistance. 


\section{Authors' contributions}

AK and NV carried out the viral load assays, genotypic drug resistance testing and interpretation, and drafted the manuscript. PK, DK, PK, TN, DN, enrolled patients and collected data on patient history. AD, MS, AS, PP, MPD, ED and MP conceived the study, participated in its design and coordination and wrote the manuscript. All authors read and approved the final manuscript.

\section{Author details}

${ }^{1}$ Laboratoire de Biologie Moléculaire et d'Immunologie (BIOLIM/FSS/UL), Université de Lomé, Lomé, Togo. ${ }^{2}$ Département des sciences fondamentales et biologiques, Faculté des Sciences de la Santé, Université de Lomé, Lomé Togo. ${ }^{3}$ UMI 233, Institut de Recherche pour le Développement (IRD)/INSERM U1175, Université de Montpellier, Montpellier, France. ${ }^{4}$ Centre Médico-Social (CMS) Kouvé, Kouvé, Togo. ${ }^{5}$ Hopital Général d'Aného, Aného, Togo. ${ }^{6}$ Centre Hospitalier Préfectoral (CHP) Kpalimé, Kpalimé, Togo. ${ }^{7}$ Centre Hospitalier Universitaire (CHU) Kara, Kara, Togo. ${ }^{8}$ Centre Hospitalier Régional (CHR) Atakpamé, Atakpamé, Togo. ${ }^{9}$ Programme National de Lutte contre le Sida (PNLS), Lomé, Togo. ${ }^{10}$ Conseil National de Lutte contre le Sida (CNLS), Lomé, Togo.

${ }^{11} 08$ B.P. 8742 , Lomé 08 , Togo.

\section{Acknowledgements}

We thank Ministry of Health in Togo for providing authorizations for the implementation of this survey. Our sincere thanks to the BIOLIM/FSS/UL laboratory Team in particular to Mr Ouro-Medeli Alassane, Mrs Ehlan-Amenya Phyllis and Mr Ali-Edje Komlan.

\section{Funding}

This study was funded by Global Fund round 8, Institut de Recherche pour le Développement IRD and The French Cooperation in Togo. Abla A. Konou is doctoral fellow from the French Foreign Office.

\section{Competing interests}

The authors declare that they have no competing interests.

Received: 22 May 2015 Accepted: 16 November 2015

Published online: 27 November 2015

\section{References}

1. Gilks CF, Crowley S, Ekpini R, Gove S, Perriens J, Souteyrand Y, et al. The WHO public-health approach to antiretroviral treatment against HIV in resource-limited settings. Lancet. 2006;368:505-10.

2. Aghokeng AF, Monleau M, Eymard-Duvernay S, Dagnra A, Kania D, Ngo-Giang-Huong N, et al. Extraordinary heterogeneity of virological outcomes in patients receiving highly antiretroviral therapy and monitored with the World Health Organization public health approach in sub-saharan Africa and southeast Asia. Clin Infect Dis. 2014;58:99-109.

3. Rusine J, Asiimwe-Kateera B, Van de Wijgert J, Boer KR, Mukantwali E, Karita $\mathrm{E}$, et al. Low primary and secondary HIV drug-resistance after 12 months of antiretroviral therapy in human immune-deficiency virus type 1 (HIV-1) infected individuals from Kigali, Rwanda. PLoS One. 2013;8:e64345.
4. Wadonda-Kabondo N, Hedt BL, Van Oosterhout JJ, Moyo K, Limbambala $\mathrm{E}$, Bello $\mathrm{G}$, et al. A retrospective survey of HIV drug resistance among patients 1 year after initiation of antiretroviral therapy at 4 clinics in Malawi. Clin Infect Dis. 2012;54(Suppl 4):355-61.

5. WHO: Antiretroviral therapy for HIV infection in adults and adolescents: recommendations for a public health approach. http://www.who.int/hiv/ pub/arv/adult2010/en/index.html (2010). Accessed 18 May 2015.

6. Dagnra AY, Vidal N, Mensah A, Patassi A, Aho K, Salou M, et al. High prevalence of HIV-1 drug resistance among patients on first-line antiretroviral treatment in Lomé, Togo. J Int AIDS Soc. 2011;14:30.

7. www.hivfrenchresistance.org (2015). Accessed 18 May 2015.

8. Hamers RL, Oyomopito R, Kityo C, Phanuphak P, Siwale M, Sungkanuparph S, et al. Cohort profile: the PharmAccess African (PASER-M) and the TREAT Asia (TASER-M) monitoring studies to evaluate resistance-HIV drug resistance in sub-Saharan Africa and the Asia-Pacific. Int J Epidemiol. 2012;41:43-54.

9. Barth RE, Tempelman HA, Moraba R, Hoepelman Al. Long-term outcome of an HIV-treatment programme in rural Africa: viral suppression despite early mortality. AIDS Res Treat. 2011;2011:434375.

10. Boullé C, Kouanfack C, Laborde-Balen G, Aghokeng AF, Boyer S, Carrieri MP, et al. Prediction of HIV drug resistance based on virologic, immunologic, clinical, and/or adherence criteria in the Stratall ANRS 12110/ ESTHER trial in Cameroon. Clin Infect Dis. 2013;57:604-7.

11. Taieb F, Aghokeng AF, Eymard-Duvernay S, Chia JE, Einterz E, Mpoudi-

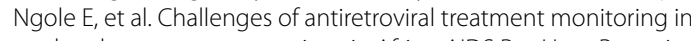
rural and remote-access regions in Africa. AIDS Res Hum Retroviruses. 2014;30:623-5.

12. Diouara AA, Ndiaye HD, Guindo I, Bangoura N, Cissé M, Tchiakpe E, et al. Antiretroviral treatment outcome in HIV-1 infected patients routinely followed up in capital cities and remotes areas of Senegal, Mali and Guinea-Conakry. J Int AIDS Soc. 2014;17:19315.

13. Liégeois F, Vella C, Eymard-Duvernay S, Sica J, Makosso L, MouingaOndémé A, et al. Virological failure rates and HIV-1 drug resistance patterns in patients on first-line antiretroviral treatment in semirural and rural Gabon. J Int AIDS Soc. 2012;15:17985.

14. Johannessen A, Naman E, Kivuyo SL, Kasubi MJ, Holberg-Petersen M, Matee MI, et al. Virological efficacy and emergence of drug resistance in adults on antiretroviral treatment in rural Tanzanie. BMC Infect Dis. 2009;9:108.

15. Wandeler G, Keiser O, Pfeiffer K, Pestilli S, Fritz C, Labhardt ND, et al. Outcomes of antiretroviral treatment programs in rural Southern Africa. J Acquir Immune Defic Syndr. 2012;59:9-16.

16. Fofana DB, Soulié C, Baldé A, Lambert-Niclot S, Sylla M, Ait-Arkoub Z, et al. High level of HIV-1 resistance in patients failing long-term first-line antiretroviral therapy in Mali. J Antimicrob Chemother. 2014;69:2531-5.

17. Fall-Malick FZ, Tchiakpe E, Ould Soufiane S, Diop-Ndiaye H, Mouhamedoune BA, Ould Horma BA, et al. Drug resistance mutations and genetic diversity in adults treated for HIV type 1 infection in Mauritania. J Med Virol. 2014;86:404-10.

18. Wallis CL, Aga E, Ribaudo H, Saravanan S, Norton M, Stevens W, et al. Drug susceptibility and resistance mutations after first-line failure in resource limited settings. Clin Infect Dis. 2014;59:706-15.

\section{Submit your next manuscript to BioMed Central and we will help you at every step:}

- We accept pre-submission inquiries

- Our selector tool helps you to find the most relevant journal

- We provide round the clock customer support

- Convenient online submission

- Thorough peer review

- Inclusion in PubMed and all major indexing services

- Maximum visibility for your research

Submit your manuscript at www.biomedcentral.com/submit

() Biomed Central 